\title{
Editorial:
}

\section{Clinical Sociology Models: Interventions and Analysis in Africa}

\author{
Mariam Seedat Khan \\ ORCID iD: https://orcid.org/0000-0001-9056-2282
}

\author{
Stanley Ehiane \\ ORCID iD: https://orcid.org/0000-0001-6871-4526
}

Clinical sociologists establish interventions and develop clinical models in pursuit of improving the lives of individuals, communities and societies. Scientific research facilitates an understanding of histories and trajectories allowing practitioners to understand social systems and the role of actors within them. Ultimately the merging of theory, methodology and practice informs successful clinical models.

Clinical sociology is the application of a variety of critically applied practices which attempt sociological diagnosis and treatment of groups and group members in the community (Glassner \& Freedman 1979: 5).

The role of clinical sociologists has become increasingly important in the global south. The bourgeoning social problems, intensified by the onset of the COVID-19 pandemic, have degenerated the difficulty of the marginalised populaces in the south. Political conflict, unemployment, derisory education and health access, gender-based violence, poverty, social dissonance, global warming, and food insecurity demand the intervention and creation of clinical interventions. Clinical sociologists engage with a multiplicity of intersecting factors working with interdisciplinary models to offer affordable interventions that improve the human condition in all societies. 
The issue of Alternation titled Clinical Sociology Models: Interventions and Analysis in Africa is a special edition of scientific papers that interlace academic scholarship with action in the form of a clinical intervention utilising a multidisciplinary approach. It works with the approach that the work of clinical sociologists effects positive change in the lives of people in varied situations. Clinical sociologists seek to engage in research that presents itself in the form of a unique social problem in a specific society.

The collection of ten scientific articles in this special edition, presents theoretical and practical advances demonstrated by clinical interventions and perspectives in Africa. The analysis of extensive contemporary social issues, development, healthcare, gender, education, terrorism, climate change, institutional culture, occupational health and safety, legislation, and policy transformation epistemologies is undertaken within a clinical context in the collection.

Clinical analysis is the critical assessment of beliefs, policies, or practices, with an interest in improving the situation. Intervention is based on continuing analysis; it is the creation of new systems as well as the change of existing systems and can include a focus on prevention or promotion (Fritz 2008: 1).

Clinical sociologists evaluate circumstances and lessen difficulties via inquiry and clinical intervention. A clinical analysis is the perilous evaluation of philosophies, policies and practices to improve the recipient's quality of life or social situation. A clinical intervention is the conception of innovative methods and techniques that challenge traditional systems, which require continuous research and development. The role of the clinical sociologist is evident at multiple levels, reaching individuals and/ or groups of people.

Even though the clinical sociologist usually specialises in one or two levels of intervention, the practitioner will move among several levels (individual, organisation and community) to analyse and, or to intervene (American Sociological Association 1999).

Scientific contributions in this issue mark the first attempt at a special Clinical Sociology edition by leading scholars exclusively from the African continent. Academics from South Africa, Botswana, Zimbabwe and Nigeria have identified unique social problems and offer frameworks for clinical interventions. 
The objective of intervention can be different in various situations. In general, an intervenor tries to help participants understand, deal with, and/ or alter a situation and may do this in any number of ways. These interventions can include undertaking needed research, critical education, training, leadership development, strategic planning and/ or assessing different kinds of actions. The tasks might be manageable or quite daunting (Fritz \& Rheaume 2014: 17).

In the next section, we provide a brief overview of the articles in this issue.

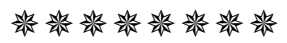

Tolulope Abiola Allo, David Imhonopi, Victor Adekunle Owoyomi and Mariam Seedat-Khan, title their article, 'A Correlational study on Perception of Vulnerability and Women's Behavioral Dispositions to Breast Cancer: Implication for Sustainable Development in Nigeria'. The article established a correlation between the perception of vulnerability and women's behavioural dispositions towards breast cancer within the context of Sustainable Development Goals (SDGs) in Ogun State, Nigeria. In its objective, the project examined, i) the relationship between women's reaction to unusual breast cancer change and worry about having breast cancer; ii) the nexus between women's attitudes towards breast cancer screening; and iii) worry about having breast cancer. The study made use of the health belief model (HBM) in its theoretical framework. It adopted a descriptive cross-sectional research design using mixed methods of data collection. A self-administered questionnaire, in-depth interviews (IDIs) and key informant interviews (KIIs) guides were the instruments adopted. A random sample size of 1000 women using four multi-stage sampling techniques for quantitative data was accessed. The qualitative data drew on 20 respondents with the use of purposive sampling. Snowball sampling was used to determine IDIs, while a convenience sampling technique was adopted for KIIs' nuclear family members, patients' acquaintances and oncology healthcare providers. The quantitative data were analysed using frequency distribution (univariate analysis) and chi-square $\left(\chi^{2}\right)$ (bi-variate analysis). Content analysis was adopted to analyse the qualitative data. Findings revealed that there is a significant relationship between women's reaction to unusual breast change and worry about having breast cancer as well as a meaningful relationship between women's attitude towards 
breast cancer screening and worrying about having breast cancer. The study concludes that health education policies and programmes ought to be developed professionally to address matters contiguous to the perception of women's vulnerability adequately. Plans ought to prioritise behavioural dispositions of breast cancer patients in Ogun State, enabling Nigeria to realise equitable, feasible and sustainable health-care.

The article by Bheki R. Mngomezulu, is titled, 'Re-examining the Nexus between Race and Higher Education in Post-colonial and Postapartheid African Contexts'. Throughout the African continent, the development of higher education was predicated on race or showed racial overtones on either side of the political divide. The colonial government wrestled with this challenge. At independence in the 1960s and 1970s, Africa's nationalist leaders invested in the reconfiguration and increase of the higher education sector. Meanwhile, they unwittingly sustained the endemic race/ higher education symmetry. The advent of South Africa's 1994 democracy mandated the reconfiguration of higher education, with a key consideration of race. Consequently, deciding on the number of higher education institutions, student and staff profile, curriculum content and resources allocation could not leave out race as one of the determining factors. As white South Africans cried foul, arguing that they were being side-lined or forced to accommodate Black students, thereby diminishing the status of their higher education institutions, Black students welcomed the new development. More than five decades since the end of colonialism, and more than twenty-five years since the demise of apartheid, race and higher education remain inseparable. Against this backdrop, this article revisits the metamorphosis of race in higher education, appreciates the sustained nexus between the two phenomena, and proffers recommendations.

In their article, Gbenga S. Adejare, Olayinka Akanle and Vera E. Abaimu, in 'Globalization and Education: Perspectives in Knowledge Production and Utilization' departs from the standpoint that one historical process and current that has defined knowledge production and utilization is that this complex has developed as if globalization does not exist. Globalization, while it has affected every component of human existence, has impacted the area of education much more that is usually assumed. Globalization affects what is known, how it is known and taught, how it is inculcated in people across generations, how it is validated, how it is utilized, how it is validated and how it is perpetuated. The existential realities across disciplines all over the world, and particularly in Africa, clearly demonstrate that globalization 
continues to be relevant in understanding ramifications of education across space and time. This article contributes to knowledge relative to the interface of globalization and education against the strategic background of disciplinary knowledge production and utilization, particularly in Africa.

In 'Academia Unplugged: Understanding the Intersec-tion of Gender and Race in the Trajectories of Black Women Academics at UKZN', Aradhana Ramnund-Mansingh and Mariam Seedat-Khan, sought to explore the career trajectories of Black women academics in South Africa. This was made possible with ten in-depth interviews conducted at all five UKZN campuses. Participants were invited to recount their lived experiences in the academy, which continue to include political vicissitudes of race and gender. Existing scholarship on challenges faced by Black women is palpable; the South African landscape is distinctive, with complex inter-sections from the oppressive apartheid state followed by the 2004 post-apartheid higher education transformation. Prominent themes that developed, when examining race and gender, included institutional culture, the 'old boys' net-work role overload, and academic bullying. The theoretical framework that underpins this study includes social constructionism. The inclusion of intersectionality contextualises experiences of race and gender incongruences in the academy, race, and gender. Notwithstanding the focus on intersectionality, experiences of exploitation are continuously perpetrated against Black women in the academy. While the legislation includes race and gender targets, which play a critical role in transformation, Black women academics face intersectional gendered challenges in apartheid-style 'bush colleges'. This continues in a postapartheid society where they are subject to gender and racial prejudices. The empirical evidence seeks to espouse Black women in academia by propositioning a framework on their historical experience and presenting the bearing that transformation has had on them exclusively. Black women, specifically, continue to be imperilled to innumerable career and personal adversities.

Titled, 'Sociology of Development and Education: An Epistemic Continental Approach', Olayinka Akanle and Gbenga Adejare, engage how Sociology of Development, as a unit of Sociology, interfaces with Education within broader ontological and epistemic constructs to agitate increased attempts for Africanist approaches as an alternative perspective to examining disciplinary interlinkages relative to Education. While there are divergent approaches and theories that culminated in Sociology of Development, a careful interrogation of how such approaches and theories are suited within the spaces 
of histories, epistemologies, cultures and ethnographies of the African landscape for effective Education is central to this article. This is not only because this subfield of Sociology in Africa is budding and relevant to general knowledge production, but also because it is consequential for the relevance of the discipline and its branches, including Sociology of Development and Clinical Sociology, on the continent of Africa and in global scholarship.

Quraisha Dawood and Mariam Seedat-Khan, 'The New Kid on the Block: How South African Tertiary Institutions Respond to the Emerging Profession of Mechatronic Engineering'. This article seeks to understand how tertiary education institutions in South Africa have formulated a strategy for students embarking on a degree programme for a fledgling profession in the field of engineering, a field that is expanding in both scope and depth. Literature on the sociology of professions connects qualification to a cultural mandate, industry demands, and accredited associations as the key determining factors for the legitimisation of a fledgling profession. Therefore, consideration is given to the aspect of a qualifications framework and how tertiary institutions understand these new professions and develop curricula for them, based on a constructivist approach to curriculum development and knowledge construction. To delve into this dynamic, the focus is on how tertiary institutions in South Africa conceptualise mechatronic engineering and equip students with the necessary skills and qualifications required, ultimately ensuring that graduates are equipped with the specialised skills required to operate as a mechatronic engineer. The scholarship provides evidence that the field of mechatronics has been subjected to haphazard expansion globally and that courses for mechatronics contrast across the world. Japan incorporated mechatronic engineering into its curricula in the 1970s, compared to South Africa, which began this process only 30 years ago, indicating evidence of the contrast. While the field continues to expand and develop in scale across disciplines, it is becoming increasingly necessary for developing economies like South Africa, to prioritise mechatronics processes for professionals to remain competitive within the global manufacturing industry. Related to this, a study on the development of mechatronic engineering courses has not been undertaken in South Africa. This predicament gives impetus to a study of this nature. Theoretically, this research contemplates gender constructs in mechatronics. Based on 50 in-depth interviews in three provinces, it considers the nature of mechatronic engineering and its accreditation status from the Engineering Council of South Africa, focusing on how six tertiary institutions across South Africa have 
designed their curricula to meet the industry's demand for mechatronic engineeers. These included the Western Cape (3), Eastern Cape (1) and KwaZuluNatal (2). Discourses among students and academics, which affect the perception of mechatronic engineers within the broader engineering fraternity, were interrogated. Based on this research, the article illustrates that constructing a qualification for an emerging qualification is an arduous process, often founded on the perceptions of the institution, its previous knowledge and directed by the demands of industry. By utilising the discipline of mechatronic engineeering, the article aims to scrutinise this practice and identify progress and challenges faced by those with first-hand experience of these mechatronic courses.

Stanley Ehiane's, 'Countering Youth Radicalisation and Extremism in Northern Nigeria: The Role of Education as a Clinical Intervention', focuses on the fact that the dynamic nature of youth extremism in Northern Nigeria has been attributed to the low level of education in the region. Research indicates the need for the development of clinical models to address radicalisation and de-radicalisation. Poverty, lack of education, isolation, exclusion, and religion are the key variables that intersect when addressing social issues that contribute to the spread of ideologies and the recruitment of youth into extremist groups. The World Bank Group (WBG) is increasingly being called upon to address the development dimensions of violent extremism by client governments and the international community. The World Bank has shied away from designing a standalone programme to counter violent extremism, from an education perspective. The risk of susceptibility to extremist ideology is determined by a multiplicity of factors, the most important being education. In Northern Nigeria, education has been compromised and has left the youth vulnerable to armed groups such as Boko Haram. Formal and quality education contributes to a climate of increased care and respect for basic human rights and peace. This article focuses on the role of education in the prevention of violent extremism (VE) and discusses the international policy framework on the significance of formal education as a tool for countering violent extremism (CVE) and contributing to peacebuilding in Nigeria. While the study is non-empirical, extensive literature was consulted across the disciplines to address the critical issues in the study. The relationship between the identified constructs' conceptual framework was subjected to intensive discourse using the ecosystem theory of Urie Bronfenbrenner. The conclusion drawn is an early warning regarding the need for a clinical response model that promotes the acquisition of formal and quality 
education for a successful soft approach to counter violent extremism and radicalisation terrorism mechanisms.

The International Labour Organisation (ILO) has developed numerous conventions, protocols, and recommendations on minimum labour standards. Some conventions have been promulgated and adopted by the ILO member states, the majority of which relate to occupational safety and health systems (OSH). In their study, titled, 'An Overview of Occupational Safety and Health Systems in Nigeria', Qudus Olawepo, Mariam Seedat-Khan and Stanley Ehiane, evaluate the OSH in Nigeria to ascertain their compliance with ILO safety standards. The evaluation includes a focus on the OSH in the food and drink sector in Nigeria. The legislation that institutes the underpinnings of the OSH system is examined against industry practices in Nigeria. They recognise that Nigeria, analogous to other African countries, had not ratified the principal ILO conventions on safety and health, in particular the ILO OSH, 1981, Number 155; and the ILO Promotional Framework for Occupational Safety and Health Convention, 2006, Number 187. The exploration of the OSH systems demonstrates that $\mathrm{OSH}$ systems in Nigeria are largely uncoordinated and weak, owing to administrative, human, technological and logistics limitations. Convention 187 requires of ratifying member countries, to formulate national OSH policies, systems, and programmes to prevent industrial accidents and minimise hazardous conditions in the workplace. Unambiguously, the convention makes it mandatory for all country signatories, to implement a coherent national OSH. The study found that Nigeria is an African signatory but that it fails to comply with this directive.

The intensifying rate of school-based violence in South Africa has become a major concern for school management, non-governmental organisations and government at large. The constant disruption of knowledge dissemination because of upheavals and conflicts within spaces of learning is diminishing the value of education and threatens the peace and serenity of South African schools. Educators and learners alike are in constant fear of their lives and wellbeing whenever they are on the school premises. Oluwatobi Joseph Alabi and Thandanani Ngidi, in, 'Our Schools are No Longer Safe: The Narratives of Educators at Peri-Urban High Schools in Umlazi, KwaZuluNatal, South Africa', argue that the escalating nature of school-based violence in locally cannot be divorced from the historical experiences of conflict and aggression as forms of resistance, that were prevalent within the country during the time of apartheid. To note too, is that violence within learning spaces in 
South Africa reflects the current prevalence of criminality within the postapartheid country. The article, through a qualitative approach, engaged 15 educators on their experiences of school-based violence in one of the most violent neighbourhoods in South Africa - Umlazi, Durban. It became evident that this menace has affected the learning process and has grave educational, social, and psychological imply-cations on learners and educators. The study recommends that a combined approach, involving all stakeholders and institutions within the society, is required to curb the growing spate of school violence. Government and stakeholders must take the issue seriously as its affects spread across the board and have an impact on the productivity and attrition rates in higher institutions of learning.

Within the last two decades, the ferocious and infernal activities of the Boko Haram as an active terrorist network, especially within the context of the Lake Chad region, have informed the conclusion that a rapid counterterrorism response is imperative. These clusters of countries (Chad, Niger, Nigeria and Cameroon) have become vulnerable to the extremism of this Islamic sect. Apart from the normal aftermath of violence such as numerous deaths and a humanitarian crisis, this conflict has assumed a dangerous twist bordering on horrific with grisly human rights abuses that often leave the local and international public shocked and dumb-founded. Even though much has been documented about the formation of the Multinational Joint Task Force (MNJTF), an initiative that aims at liquidating the terrorists, the atrocities have persisted. Stanley Ehiane and Caleb Ayuba, in, 'A Human Rights Approach to the Lake Chad Region's Counter-Terrorism Strategy' aims at advocating an end to all forms of human rights abuses perpetrated by the Boko Haram through a concerted collaboration between national authorities and regional and international institutions. The article also supports the MNJTF to rise to its responsibility by adhering to all human rights protocols and rules of engagement $(\mathrm{RoE})$ in its regional security management engagements. This can be achieved through a greater appreciation of all human rights doctrines as codified in the Universal Declaration of Human Rights documents of the United Nations (UN) and the African Charter on Human and Peoples Rights/ Banjul Charter of the African Union (AU), amongst others. To develop its perspectives, the article deploys existing literature describing the violent conflicts, and various human rights articles which were extracted and analysed using the desktop approach.

Ostensibly, there is an intensifying need for the development and en- 
hancement of the proficiencies and dexterities of clinical sociologists to address ever deepening social problems. This Alternation issue, arrives at an imperative time in the global south, opening a space that may buttress academic and practitioner capabilities in the region, recognising the value and capabilities that clinical interventions and analysis may offer.

We anticipate that scholars who engage with the ten articles in this special edition of Alternation might find it helpful to increase their contribution to developing global south solutions to deep-seated and established and existing social problems. Aimed at forms of constructive social intervention, Clinical Sociologists aim to assist in the analyses of such problems but also in the constructing of alternative social systems, serving the wellbeing of all equally.

\section{References}

American Sociological Association 1999. Careers in Sociology. $5^{\text {th }}$ Edition. Washington, DC: American Sociological Association Teaching Resources Centre.

Glassner, B. \& F. Jonathan 1979. Clinical Sociology. New York: Longman. Fritz, J.M. 2008. International Clinical Sociology. New York: Springer. https://doi.org/10.1007/978-0-387-73827-7

Fritz, J.M. \& J. Rheaume 2014. Community Intervention Clinical Sociology Perspectives. New York: Springer. https://doi.org/10.1007/978-1-49390998-8_2

Professor Mariam Seedat Khan CCS

Society and Social Change

School of Social Science

University of KwaZulu-Natal

Seedatm@ukzn.ac.za

Dr. Stanley Ehiane

The Institute of Social and Economic Research (FHISER)

University of Fort Hare

Eastern Cape

South Africa

Stanleyehiane@yahoo.com 